\title{
ОСОБЕННОСТИ ПРАВОВОГО РЕГУЛИРОВАНИЯ ЭКОНОМИЧЕСКОЙ БЕЗОПАСНОСТИ СУБЪЕКТОВ ХОЗЯЙСТВОВАНИЯ
}

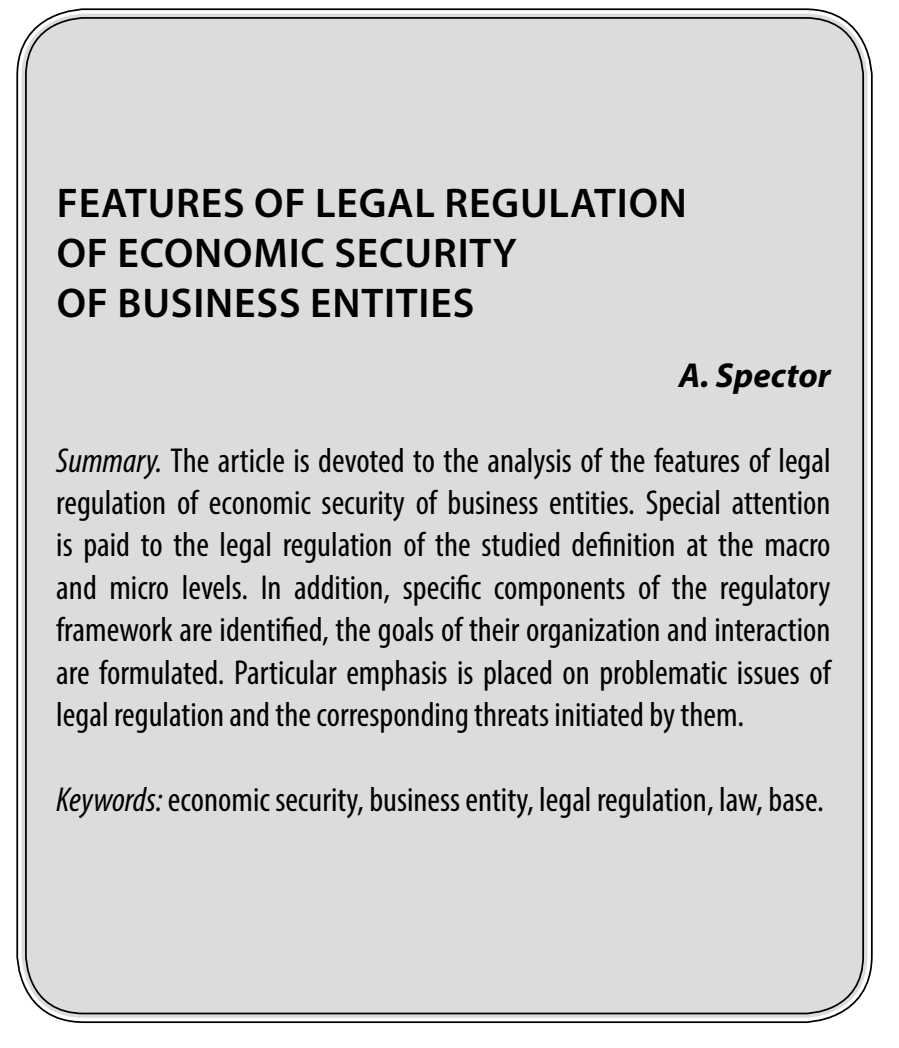

Summary. The article is devoted to the analysis of the features of legal regulation of economic security of business entities. Special attention is paid to the legal regulation of the studied definition at the macro and micro levels. In addition, specific components of the regulatory framework are identified, the goals of their organization and interaction are formulated. Particular emphasis is placed on problematic issues of legal regulation and the corresponding threats initiated by them.

Keywords: economic security, business entity, legal regulation, law, base.

\author{
Спектор Асия Ахметовна \\ Д.ю.н., nрофессор, Российский университет \\ транспорта, г. Москва \\ spector.a@mail.ru
}

Аннотация. Статья посвящена анализу особенностей правового регулирования экономической безопасности субъектов хозяйствования. Отдельное внимание уделено законодательному обеспечению исследуемой дефиниции на макро и микроуровне. Кроме того, выделены конкретные компоненты нормативно-правовой базы экономической безопасности, сформулированы цели их организации и взаимодействия. Особый акцент сделан на проблемных моментах правового регулирования и соответствующих угрозах, инициированных ими.

Ключевые слова: экономическая безопасность, субъект хозяйствования, правовое регулирование, закон, база. овременные условия развития рыночной экономики приводят к появлению новых непредсказуемых угроз, возникающих в процессе функционирования субъектов хозяйствования. Безопасность предпринимательской деятельности на сегодняшний день является весомой компонентой национальной безопасности и конкурентоспособности страны в целом. Защищенность экономических интересов предприятий обеспечивает их устойчивое функционирование и развитие, способствует росту экономики, формированию здоровой конкурентной среды и условий для привлечения инвестиций [1].

Более того, существует двусторонняя связь между экономической безопасностью государства и экономической безопасностью субъектов хозяйствования, которая с использованием каналов общепринятого правового регулирования и контроля призвана обеспечивать оценку реального состояния защищенности и стабильности экономической системы страны, определять степень соответствия нормативно-правовых актов реалиям развития субъектов хозяйствования, качественно и своевременно корректировать правовое поле при по- явлении новых вызовов и угроз во внутренней и внешней среде [2]. Поэтому одной из главных задач любого современного предприятия является обеспечение его собственной экономической безопасности, которая в определенной степени зависит от и государства, поскольку именно государство через соответствующие органы формирует условия, в том числе и законодательные рамки, в которых предприятие создается, функционирует и развивается.

Государство посредством законодательного и нормативно-правового регулирования выступает гарантом безопасности субъектов хозяйствования. Однако, следует отметить, что не всегда условия, которые создает государство с целью обеспечения безопасности предприятия, являются благоприятными и достаточными. Это можно объяснить выявлением случаев противоречий и коллизий, встречающихся в современной законодательной и нормативно-правовой базе. Кроме того, например, технология рейдерства основана на несовершенстве законодательства и недостаточном правовом обеспечении экономической безопасности хозяйственных структур. Использование правовых методов дает 
злоумышленникам возможность обанкротить и в последующем ликвидировать предприятия, учреждения и организации различных видов экономической деятельности.

С учетом вышеизложенного, важность нормативно-правового обеспечения безопасности субъектов хозяйствования трудно переоценить. Бесспорно, надлежащее законодательное регулирование еще не гарантирует безопасности, но без его создания и постоянного усовершенствования эффективное функционирование системы экономической безопасности предприятий практически невозможно.

Таким образом, исследование проблематики правового обеспечения экономической безопасности субъектов хозяйственной деятельности является актуальным, теоретически и практически значимым.

Существенный вклад в исследование и решение проблем, связанных с обеспечением безопасности субъектов хозяйствования, внесли такие отечественные ученые-экономисты и юристы, как Р.А. Банк, Д. А. Беззубов, А.Н. Громова, В.В. Добровольская, М. Исаков, А.В. Клим, В. Козаченко.

Изучению организационно-правового обеспечения защиты информации, составляющей коммерческую тайну, в системе экономической безопасности предприятия посвятили свои труды А.В. Сердюченко, Л.С. Худолей, Л.А. Чистоклетов, Ю.В.Бондарчук, А.И. Марущак, А. А. Кириченко, В.С. Сидак и др.

Однако перманентный рост количества угроз и рисков функционирования субъектов хозяйствования, в частности в правовом поле, недостатки и пробелы в нормативно-правовой базе, регулирующей создание и деятельность бизнес-структур, актуализируют необходимость проведения комплексных научных исследований в области поддержания надлежащего уровня правового обеспечения экономической безопасности субъектов хозяйственной деятельности.

Итак, с учетом вышеизложенного, цель статьи заключается в конкретизации современных принципов правового обеспечения экономической безопасности субъектов хозяйствования.

Большинство ученых рассматривает проблему законодательного регулирования системы безопасности субъектов хозяйствования в плоскости создания внутренней корпоративной нормативной базы для регламентации таких вопросов, как охрана коммерческой тайны, соблюдение режима и работы с документами и тому подобное [3]. Однако, по мнению автора, систе- ма экономической безопасности предприятия будет действенно функционировать только в условиях создания эффективного законодательства, регулирующего все аспекты хозяйственной деятельности. В связи этим, для решения обозначенных проблем необходимо проводить углубленный анализ взаимосвязи между общегосударственным законодательством и нормативными актами предприятия.

Таким образом, считаем, что основу правового обеспечения экономической безопасности субъектов хозяйственной деятельности на макроуровне должны составлять законодательные акты:

- определяющие базу правового обеспечения экономической безопасности предприятий на уровне государства;

- регулирующие различные отрасли и сферы экономической безопасности субъектов хозяйственной деятельности;

- закрепляющие стратегию развития экономической безопасности как на микро-, так и на макроуровне;

- регламентирующие направления устойчивого роста и развития национальной экономики, а также общества в целом с целью обеспечения экономической безопасности страны и ее субъектов.

Принимая во внимание вышеизложенное, представляется, что нормативно-правовое обеспечение экономической безопасности субъектов хозяйствования следует рассматривать как системный процесс, направленный на формирование организационных и законодательных основ построения, функционирования и развития системы государственного регулирования и контроля экономической безопасности предприятий.

В этом процессе должны сочетаться следующие взаимосвязанные и взаимозависимые компоненты: во-первых, определение концепции и политики нормативно-правового обеспечения экономической безопасности субъектов хозяйствования; во-вторых, создание оптимальной структуры уполномоченных органов государственной и местной власти, в обязанности которых будет входить обеспечение и контроль за деятельностью предприятий; в-третьих, нормативно-методическое обеспечение механизмов диагностики основных критериев экономической безопасности субъектов хозяйствования с целью заблаговременной идентификации источников возникновения и видов угроз; в-четвертых, разработка конкретных путей противодействия внутренним и внешним угрозам для реализации государственной политики в сфере экономической безопасности на различных иерархических уровнях; в-пятых, корректировки нормативно-правовой базы в случае необходимости. 
Ключевыми целями эффективной организации и взаимодействия выше обозначенных компонентов являются следующие:

- законодательное обеспечение свободы конкуренции между предпринимателями, в том числе защита их самих и потребителей от каких-либо проявлений монополизма и недобросовестной конкуренции;

- обеспечение всех субъектов хозяйствования равными правами и создание равных возможностей для доступа и использования материальных, технических, финансовых, трудовых, информационных, природных и других ресурсов;

- гарантии неприкосновенности имущества и обеспечение защиты прав собственности предприятия;

- разработка и внедрение стимулирующей налоговой и финансово-кредитной политики;

- стимулирование инновационной деятельности за счет целевых субсидий, налоговых льгот, целевых кредитов и т.д.;

- создание благоприятной правовой среды для развития различных форм кооперативных связей и самоорганизации субъектов хозяйствования;

- формирование современного правового поля для функционирования служб безопасности субъектов хозяйствования, детективных фирм, аналитических и консалтинговых агентств.

Как уже отмечалось ранее, чтобы в полной мере обеспечить экономическую безопасность предприятия, необходимо осуществлять юридическое сопровождение каждой сферы его деятельности как во внешней, так и во внутренней среде.

Таким образом, на следующем этапе исследования рассмотрим более подробно содержание комплексной правовой системы экономической безопасности субъекта хозяйствования на микроуровне, в состав которой должны входить следующие элементы.

1. Корпоративная безопасность. Обеспечивает прозрачные взаимоотношения между партнерами по бизнесу, препятствует захвату предприятия извне, не дает возможность нарушать нормальный порядок работы органов управления предприятия [4].

2. Безопасность отношений с контрагентами. Препятствует возникновению ситуаций, когда невозможно вернуть средства за невыполнение контрагентами своих обязательств, обеспечивает возможность быстрого применения к контрагентам правовых мер государственного принуждения.

3. Безопасность активов. Безопасность материальных активов, недвижимости оборудования, то- варов, а также безопасность интеллектуальной собственности, средств идентификации и тому подобное.

4. Безопасность в сфере трудовых отношений. Предусматривает выстраивание политики управления трудовыми ресурсами, что делает возможным их эффективное использование и снижение рисков от проверок контролирующих органов.

5. Юридическая безопасность владельцев бизнеса. Система мер, направленная на избежание ситуаций, при которых владельцы бизнеса могут быть привлечены к субсидиарной ответственности за действия юридического лица.

Изучение опыта как развитых, так и развивающихся стран позволят сделать вывод, что основными недостатками нормативно-правового обеспечения системы экономической безопасности субъектов хозяйствования является нечеткость, неполнота, нестабильность и противоречивость норм действующей нормативно-правовой базы; несогласованность между разработчиками и бессистемность нормативно-правовых актов, регулирующих экономическую безопасность предприятия; несовершенство законодательства, значительные пробелы в правовом поле [5].

Обозначенные недостатки в свою очередь приводят к возникновению целого спектра угроз правовому обеспечению экономической безопасности субъектов хозяйствования в составе которых можно выделить: недостаточную правовую защищенность интересов субъектов хозяйствования в договорной документации; преследование собственных политических и других целей партиями (общественными движениями), находящихся у власти; частая смена нормативно-правовых актов по вопросам собственности, хозяйственного и трудового права, налогообложения; нарушение юридических прав предприятия и его работников; нарушение норм патентного права; низкая квалификация сотрудников юридических служб органов власти.

Таким образом, резюмируя полученные результаты можно сделать следующие выводы. Нормативно-правовое обеспечение системы экономической безопасности субъектов хозяйствования является определяющим в формировании ее направлений, форм и способов организации. В то же время несовершенство необходимых нормативно-правовых норм или их полное отсутствие, наряду с ростом современных глобализационных вызовов и деструктивных угроз, требует постоянной адаптации и реформирования соответствующего нормативно-правового обеспечения и жестокого контроля за соблюдением законодательных норм. 
Не подлежит сомнению тот факт, что эффективная нормативно-правовая база экономической безопасности субъектов хозяйствования призвана создавать совокупность действующих факторов, условий и предпосылок для обеспечения конкурентоспособности на- циональной экономики и ее устойчивого стратегического развития, которые будут способствовать высокому уровню экономической безопасности предпринимательства, экономическому росту страны, повышению социального положения населения в целом.

\section{ЛИТЕРАТУРА}

1. узьмина Е. Е. Инновационная деятельность российских предприятий и её влияние на экономическую безопасность страны // Экономика и управление в машиностроении. 2019. № 3. С. 28-32.

2. Иванов П.И., Анников А. В. Система оперативно-разыскного обеспечения экономической безопасности предприятий оборонно-промышленного комплекса // Безопасность бизнеса. 2019. № 1. С. 11-18.

3. Авдеев В. А. Актуальные вопросы правового регулирования экономической деятельности в контексте обеспечения экономической безопасности: федеральный и региональные аспекты // Банковское право. 2019. № 2. С. 66-73.

4. орчагина Я. Ю. Правовое обеспечение экономической безопасности предприятия // Студенческий. 2019. № 22-4(66). С. 16-20.

5. Виторшкина А. А. Теоретические аспекты формирования стратегии обеспечения экономическо-правовой безопасности организации // Фундаментальные науки и современность. 2019. № 7(28). С. 30-39.

(с Спектор Асия Ахметовна ( spector.a@mail.ru )

Журнал «Современная наука: актуальные проблемы теории и практики»

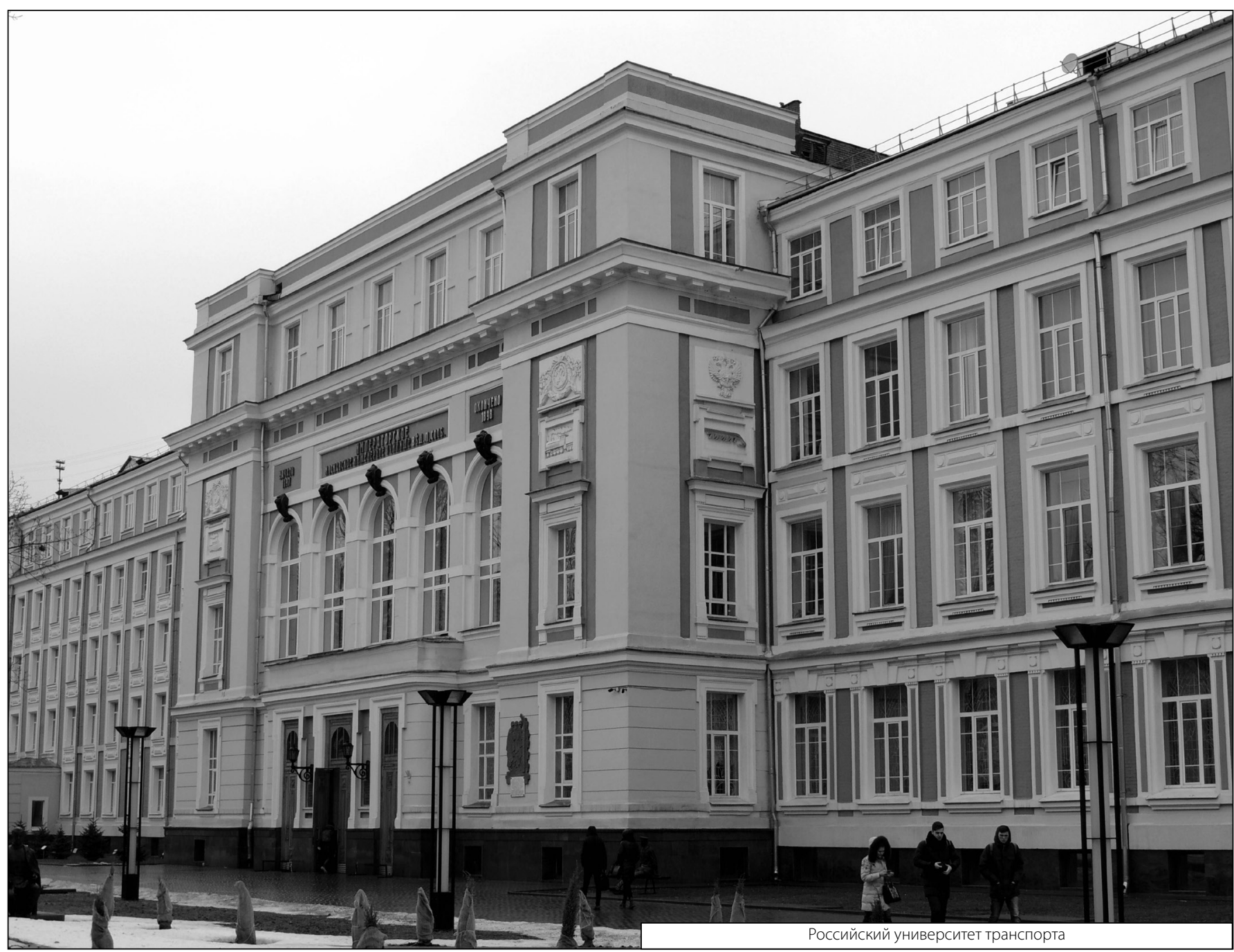

